\title{
Non-immunologic hydrops fetalis: a review of 27 cases
}

\author{
P J ILIFF, J M NICHOLLS, J W KEELING, AND J D GOUGH \\ Departments of Neonatal Paediatrics and Paediatric Pathology and Nuffield Department of Obstetrics, \\ John Radcliffe Maternity Hospital, Oxford
}

SUMMARY Twenty seven babies with severe non-haemolytic hydrops fetalis were born during a $7 \frac{1}{4}$ year period (1/1400 total births). Thirteen were live born and admitted to the intensive care nursery, but only three survived. The survivors differed from those live born infants who died in the neonatal period in that the cause of the hydrops was discovered antenatally, their serum concentrations of total protein and albumin were normal, and they had no structural anomaly. A scheme of investigation of the severely hydropic fetus in the antenatal period is outlined and the role of active obstetric management is evaluated.

Rhesus haemolytic disease is no longer the commonest cause of hydrops fetalis in the United Kingdom. Increasing attention is now focused on the miscellaneous group of non-haemolytic hydrops fetalis in which the prognosis remains very poor. We describe the outcome in 27 in-born infants with severe nonhaemolytic fetal hydrops and, in the light of the findings in these infants and in other published reports, suggest how antenatal investigation could be used to identify infants with this disorder who are likely to be born alive and to survive.

\section{Patients and methods}

In this report, hydrops fetalis was defined as severe when clinical or ultrasound examination of the fetus showed generalised oedema of greater than $5 \mathrm{~mm}$ thickness and ascites, with or without other serous effusions. Between January 1976 and March 1983 in this hospital 27 infants with severe non-rhesus hydrops were born after 28 weeks' gestation, out of 37866 total births at 28 weeks' gestation or more (an incidence of 1/1400). Fourteen of these infants were stillborn and the 13 live born babies were admitted to the intensive care nursery.

Details of the babies are shown in Table 1. Gestational age at birth ranged from 28-39 weeks (mean 33 weeks) and birthweight from $0.92 \mathrm{~kg}-4.39$ $\mathrm{kg}$ (mean $2.23 \mathrm{~kg}$ ). In 12 cases the diagnosis of hydrops fetalis was made in the antenatal period by ultrasound or radiographic examination, but in three intrauterine death of the fetus had already occurred. In four cases the clinical diagnosis of polyhydramnios was confirmed by ultrasound scan but fetal hydrops was not recognised.
A cause for the fetal hydrops was found before birth in five fetuses; one was a twin, in two there was fetal tachycardia, in one a placental angioma was visualised by ultrasound, and in the fifth a tumour arising from the cardiac ventricular mass was identified.

Delivery of the live born infants was by emergency caesarean section in five and by elective caesarean section in two: 6 babies were delivered vaginally, three with the assistance of forceps. Eleven infants had an Apgar score of 4 or less at one minute and were intubated at birth. The two who were not intubated had an Apgar score of 8 at one minute. Thirteen of the 14 stillborn infants were delivered vaginally; only one presented breech and three deliveries were effected with forceps. In one, emergency caesarean section was performed for fetal distress.

Only three of the 12 babies in whom serum total proteins were measured had a value of more than $45 \mathrm{~g} / 1$ and only three of the 11 babies in whom serum albumin was measured had a value of more than $28 \mathrm{~g} / \mathrm{l}$. These values are at the lower limit of the normal range for newborn babies in our laboratory. No evidence of haemolysis, blood group incompatibility, congenital infection, or chromosome abnormality was found in any baby. Three of the live born babies survived while the other 10 died between 15 minutes and 3.5 weeks of age. Seven died within 24 hours of birth.

\section{Aetiology}

The pathological findings in these babies are presented in detail elsewhere. ${ }^{1}$ 


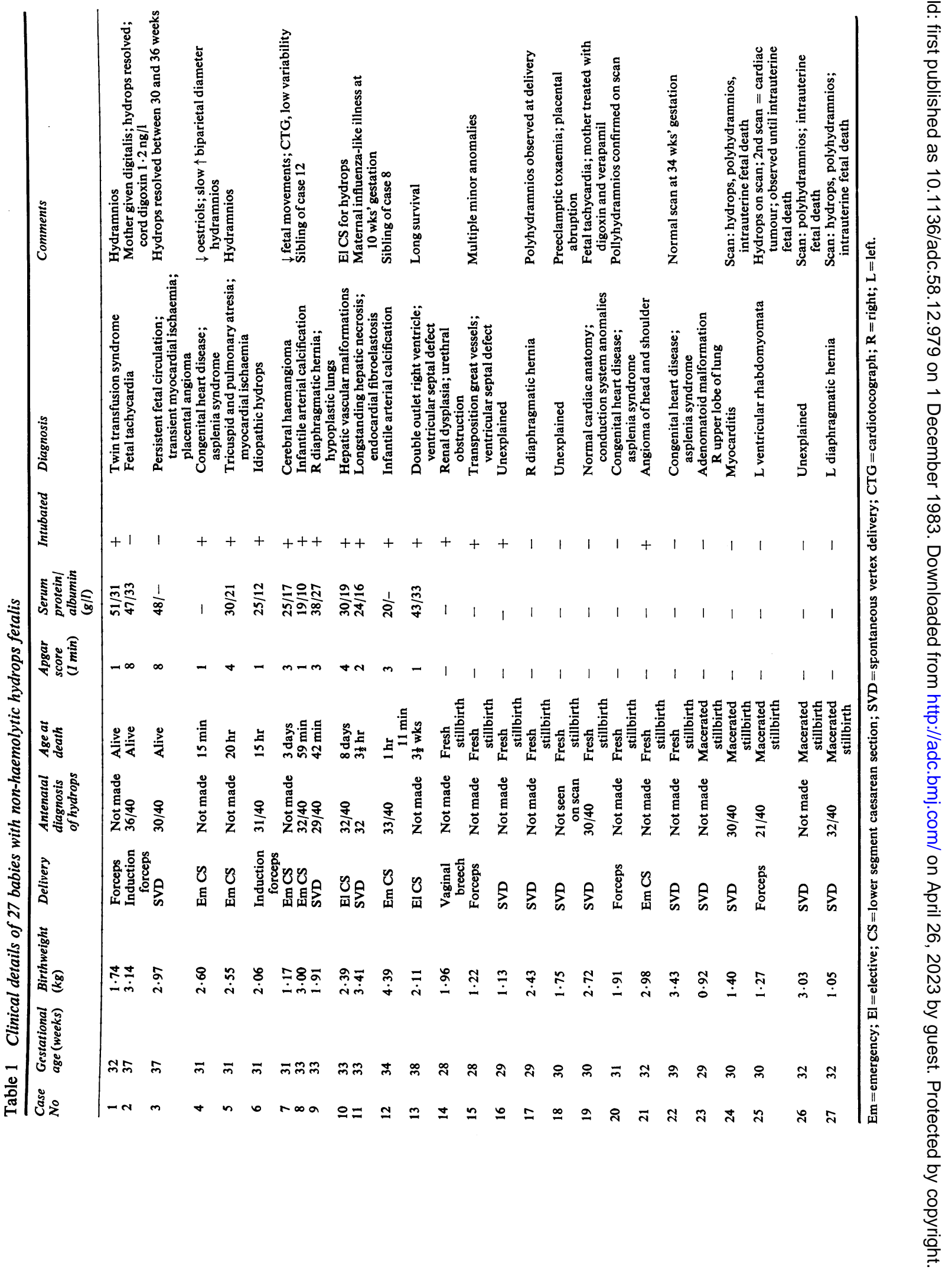


In 23 babies, a factor that could be aetiologically associated with the hydropic state was identified: of the four unexplained cases, only one was live born. In 6 babies (cases 4, 5, 13,15, 20, and 22) major structural defects of the heart and great vessels were found at necropsy, three of these being a manifestation of the asplenia syndrome. In four other babies cardiac abnormalities were found: case 11 had endocardial fibroelastosis with hepatic necrosis and fibrosis, case 19 had an anatomically normal heart but conduction system anomalies were shown histologically, case 25 had rhabdomyomata arising from the left ventricular myocardium, and case 24 had histological evidence of myocarditis.

Cases 8 and 12 were siblings; both had cardiac enlargement with biventricular hypertrophy and calcification of both systemic and pulmonary arteries in association with arterial elastic tissue. Three babies (cases 7, 10, and 21) had fetal vascular malformations and in case 3, who was found to be severely hydropic in utero at $\mathbf{3 0}$ weeks' gestation, a placental anomaly was identified in ultrasound examination and thought to be a placental angioma. This became smaller during the ensuing 7 weeks with progressive resolution of fetal hydrops seen on serial ultrasound examination. The baby was delivered after spontaneous labour at 37 weeks and suffered transient tachypnoea with cyanosis thought to be due to persistent pulmonary hypertension. Recovery was complete, however, and the infant remains well. The presence of a placental angioma was confirmed after birth.

Three babies had diaphragmatic hernias (cases 9 , 17, and 27), two of these were right side lesions. One stillborn infant (case 23) had an adenomatoid malformation affecting the right upper lobe of the lung. Case 14 had bilateral renal dysplasia and urethral obstruction. A total of five babies had defects associated with severe hypoplasia of one or bothlungs.

Case 1 was the first of twins. He had a packed cell volume (PCV) at birth of $37 \%$ and haemoglobin of $12 \cdot 1 \mathrm{~g} / 1$ (his twin had a PCV of $45 \%$ ). At birth his respiratory efforts were weak and gasping, the umbilical arterial blood pH was 7.05 , he required ventilatory assistance for 18 hours, but recovered completely. Case 2 had fetal tachycardia in association with severe hydrops diagnosed at 36 weeks' gestation. The mother was given digitalis, the fetal heart rhythm returned to normal, the hydrops resolved, and the baby was born a week later with mild oedema only.

\section{Discussion}

The decreasing incidence of rhesus haemolytic disease coupled with increased use of high resolution ultrasound equipment in obstetric departments has resulted in an increase in the antenatal recognition of non-immunological hydrops. Published reports on non-haemolytic hydrops fetalis usually conclude with a plea for better diagnosis, early intervention, and active neonatal care, ${ }^{2-4}$ although some disagree. ${ }^{5}$ The experience of Etches and Lemons ${ }^{2}$ is widely quoted in support of active management, but their study did not take into account the variation in the severity of hydrops. According to our descriptive criteria only 6 of their 22 cases would be classified as severe hydrops fetalis: two of the 6 survived.

The recent report by Hutchison et al. ${ }^{4}$ describing 10 years' experience of non-haemolytic hydrops fetalis claims that $50 \%$ of their 61 cases were potentially 'salvageable', although only one baby actually survived. It is noteworthy that in the preceding 12 years (1958-1969) the same centre reported only two surivors out of 33 cases $^{6}$ - a finding that does not add weight to the argument that more aggressive management should improve outcome.

Although the number of pathological abnormalities associated with fetal hydrops is large, ${ }^{7}$ the mechanism of non-immunological hydrops fetalis remains obscure as indeed does fetal and neonatal oedema in general. ${ }^{8}$ In 22 of our 27 babies there were abnormalities that might have produced intrauterine heart failure: complex cardiac defects (cases $4,5,13,15,20$, and 22), endocardial fibroelastosis (case 11), myocarditis (case 24), left ventricular rhabdomyoma (case 25), tachycardia (cases 2 and 19), high cardiac output (cases 1,3,7,10, and 21), or high peripheral resistance (cases 8 and 12). Cases 9 , 17,23 , and 27 had defects affecting thoracic viscera producing mediastinal displacement that could have obstructed venous return from the placenta.

Three features distinguish the three babies who survived from those who died in the neonatal period. Firstly, an underlying cause for the fetal hydrops was discovered antenatally in all three survivorsnamely multiple pregnancy, fetal tachycardia, and placental angioma - but in none of those who died. Secondly, serum total protein concentrations in the survivors were greater than $45 \mathrm{~g} / 1$ and serum albumin concentrations were more than $28 \mathrm{~g} / 1$ in the two babies in whom it was measured. Apart from one baby (case 10) with relatively normal total protein and albumin values (43 and $33 \mathrm{~g} / 1$ respectively), infants who died generally had lower concentrations of total protein. Thirdly, none of the survivors had a fetal structural abnormality.

Three of the four infants in whom no pathological abnormality that might have been related to the hydropic state was found, were stillborn and in only one was ultrasound examination performed while 
Table 2 Investigation of the mother carrying a hydropic fetus to determine subsequent management

\begin{tabular}{l} 
Investigations \\
Blood and rhesus group \\
Haemolysins, haemaglutinins \\
Minor blood group antigens \\
Kleihauer \\
Serological tests for syphilis \\
Maternal haemoglobin value \\
Glucose tolerance test \\
Ultrasonography - heart rate \\
$\qquad$-multiple pregnancy \\
$\quad$ - - - malfority of hydrops \\
\hline
\end{tabular}

the fetus was alive. Recent experience of the investigation of non-immunologic hydrops using ultrasound for fetal evaluation has resulted in the identification of an associated abnormality-in particular fetal tachycardia that may be the only abnormality or may accompany congenital cardiac malformation-in a much higher proportion of cases 910 than had been found hitherto. ${ }^{64}$

The importance of identifying antenatally a cause for fetal hydrops is to make it possible to select those few cases where immediate delivery may save the fetus or where active antenatal treatment and planned delivery may improve the chance of survival. These conditions include minor blood group abnormalities (anti e, B, C, or Kell), ${ }^{6}{ }^{11}$ fetal cardiac arrhythmias, ${ }^{311-18}$ placental chorioangioma, ${ }^{5619}$ twin-twin transfusion syndrome, ${ }^{6}$ feto-maternal haemorrhage, ${ }^{320}$ maternal anaemia, ${ }^{60}$ and maternal diabetes mellitus. ${ }^{9}$ Investigation of the mother (Table 2) should therefore exclude these conditions as far as possible. Antenatal ultrasound examination may identify severe congenital deformities, ${ }^{1021}$ which in our experience cannot be viewed as a justification for immediate delivery. Reports of the spontaneous intrauterine resolution of fetal hydrops ${ }^{22}$ (case 12) also counsel against universal early delivery in the supposed interest of the fetus. Our conclusions affect only cases where there is notable subcutaneous fetal oedema (more than $5 \mathrm{~mm}$ skin thickness) and serous effusions on ultrasonography. Once the antenatal diagnosis of severe non-haemolytic hydrops fetalis has been made, a simple scheme of investigation (Table 2) should identify fetuses who may benefit from early intervention or treatment. It is inadvisable to submit mothers of hydropic fetuses to routine early caesarean section or to embark on prolonged intensive care after a definite diagnosis of lethal congenital fetal abnormality has been made.

We gratefully acknowledge the help and encouragement of Drs J D Baum and A R Wilkinson and thank Professor A C Turnbull for constructive criticism of the manuscript, and Professor R H Anderson for examining the cardiac conduction system of case 19.

\section{References}

1 Keeling JW, Gough DJ, Iliff PJ. The pathology of nonrhesus hydrops. Diagn Histopathol 1983;6:89-111.

2 Etches PC, Lemons JA. Non-immune hydrops fetalis: report of 22 cases including 3 siblings. Pediatrics 1979; 64:326-32.

3 Perlin BM, Pomerance JJ, Schifrin BS. Non-immunologic hydrops fetalis. Obstet Gynecol 1981 ;57:584-8.

4 Hutchison AA, Drew JH, Yu VYH, Williams ML, Fortune DW, Beischer NA. Nonimmunologic hydrops fetalis: a review of 61 cases. Obstet Gynecol 1982;59: 347-52.

5 Maidman JE, Yeager C, Anderson V, et al. Prenatal diagnosis and management of nonimmunologic hydrops fetalis. Obstet Gynecol 1980;56:571-6.

6 Macafee CAJ, Fortune DW, Beischer NA. Nonimmunological hydrops fetalis. J Obstet Gynae Brit Comm 1970;77:226-37.

7 Machin GA. Differential diagnosis of hydrops fetalis. Am J Med Genet 1981 ;19:341-50.

8 Barnes SE, Bryan E, Harris D, Baum JD. Oedema in the newborn. In: Baum $\mathbf{H}$, Gergely J, eds. Molecular aspects of medicine. Oxford: Pergamon Press, 1977.

- Fleischer AC, Killam AP, Boehm FH, et al. Hydrops fetalis: sonographic evaluation and clinical implications. Radiology 1981 ;141 :163-8.

10 Kleinman CS, Donnerstein RL, DeVore GR, et al. Fetal echocardiography for evaluation of in utero congestive heart failure. A technique for study of nonimmune fetal hydrops. N Engl J Med 1982;306:568-75.

11 Lorch V, Nelson RA, Meyers A, Carroll D, Mierau E. Hydrops fetalis: a review of seven cases. J Kans Med Soc 1979;80:503-20.

12 Van der Horst RL. Congenital atrial flutter and cardiac failure presenting as hydrops foetalis at birth. $S$ Afr Med $J$ 1970;44:1037-9.

13 Altenburger KM, Jedziniak M, Roper WL, Hernandez J. Congenital complete heart block associated with hydrops fetalis. J Pediatr 1977;91:618-20.

14 Valerius NH, Jacobsen JR. Intrauterine supraventricular tachycardia. Acta Obstet Gynecol Scand 1978;57:407-10.

15 Newburger JW, Keane JF. Intrauterine supraventricular tachycardia. J Pediatr 1979;95:780-6.

16 Cooke RWI, Mettau JW, Van Coppelle AW, De Villeneuve VH. Familial congenital heart block and hydrops fetalis. Arch Dis Child 1980;55:479-80.

17 Rees L, Vlies PR, Adams J. Hydrops fetalis, an unusual cause, presentation and method of diagnosis. Case report. BrJ Obstet Gynaecol 1980;87:1169-70.

18 Shirley IM, Richards BA, Ward RH. Ultrasound diagnosis of hydrops fetalis due to fetal tachycardia. $\mathrm{Br} J$ Radiol 1981;54:815-7.

19 Sweet L, Reid WD, Roberton NRC. Hydrops fetalis in association with chorioangioma of the placenta. J Pediatr $1973 ; 82: 91-4$.

20 Debelle GD, Gillam GL, Tauro GP. A case of hydrops fetalis due to foetomaternal haemorrhage. Aust Paediatr $J$ 1977;13:131-3.

21 Hadlock FP, Deter RL, Garcia-Pratt J, et al. Fetal ascites not associated with $R h$ incompatibility: recognition and management with sonography. $A J R$ 1980;134: 1225-30.

22 Platt LD, Collea JV, Joseph DM. Transitory fetal ascites: an ultrasound diagnosis. Am J Obstet Gynecol 1978;132:906-8.

Correspondence to Dr P J Iliff, Department of Neonatal Paediatrics, John Radcliffe Maternity Hospital, Headington, Oxford OX3 9DU.

Received 12 August 1983 